\title{
Long-term treatment of chronic plaque psoriasis with biological drugs can control platelet activation: targeting the bridge between inflammation and atherothrombosis
}

\author{
Bartłomiej Kwiek ${ }^{1}$, Joanna Narbutt ${ }^{2}$, Anna Sysa-Jędrzejowska³, Andrzej Langner ${ }^{1}$, Aleksandra Lesiak ${ }^{2}$
}

'Department of Dermatology and Immunodermatology, Medical University of Warsaw, Warsaw, Poland 2Department of Dermatology, Medical University of Lodz, Lodz, Poland

${ }^{3}$ Department of Social Sciences, University of Social Sciences, Lodz, Poland

Adv Dermatol Allergol 2017; XXXIV (2): 131-137

DOI: https://doi.org/10.5114/ada.2017.67077

\begin{abstract}
Introduction: Platelet activation is elevated in moderate to severe psoriasis, and the reduction in platelet activation during short-term treatment has already been demonstrated. Soluble P-selectin is a well-established marker of platelet activation.

Aim: To show whether the long-term treatment of psoriasis with biological drugs can reduce elevated platelet activation.

Material and methods: An observational study of 27 patients with chronic plaque psoriasis, treated with infliximab, adalimumab, etanercept, or ustekinumab for up to 12 months was conducted. Psoriasis area and severity index (PASI), serum P-selectin and interleukin (IL)-6 were monitored throughout the treatment.

Results: There was no significant correlation between PASI and platelet activation in our patients. After 3 months of treatment, a significant reduction in PASI and IL-6 was found, while P-selectin was not significantly reduced. When a cohort of patients who had shown elevated P-selectin prior to the treatment was evaluated, a significant reduction in P-selectin was observed in all 8 patients following 3 months; a reduction that was sustained after 6 and 12 months of therapy.

Conclusions: We conclude that PASI is not a good predictor of platelet activity in patients with PASI near to 10. Biological drugs reduce platelet activation in patients who have increased platelet activation prior to treatment, and this effect is stable during chronic therapy.
\end{abstract}

Key words: psoriasis, atherothrombosis, comorbidities, platelets, P-selectin, biological.

\section{Introduction}

Psoriasis is a chronic inflammatory disease. In the course of moderate to severe psoriasis, local inflammatory events in the skin occur in parallel with the systemic hyperinflammatory status reflected by elevated proinflammatory cytokines such as tumor necrosis factor $\alpha$ (TNF- $\alpha$ ), interleukin (IL)-12, IL-23, and IL-6 [1].

Chronic inflammatory diseases, including psoriasis, may be associated with an increased risk of cardiovascular disease (CVD) [2-4]. Severe chronic plaque psoriasis is estimated to reduce lifespan by 3-4 years, and this could be at least in part related to CVD. Psoriasis has been shown to worsen the prognosis following myocardial infarction [5].

There are several hypotheses concerning the link between the pathophysiology of psoriasis and CVD [6-9].
Platelets are one of the key players in the pathogenesis of atherothrombosis and CVD, and their activation is a risk factor for the outcome of myocardial infarction, stroke, and pulmonary embolism [10, 11]. Antiplatelet treatment reduces the morbidity and mortality in the course of CVD [12].

Platelet activation has been shown in several studies to be elevated in moderate to severe psoriasis, and this seems to be correlated with disease severity [13-19]. Yet the significance of antiplatelet treatment for psoriasis comorbidities and psoriasis comorbidity-related deaths remains unknown. Reductions in platelet activation during short-term antipsoriatic treatment has already been shown; however, there has been only one report on the effect of long-term treatment $[13,14,16,18]$. Biological treatments targeting TNF- $\alpha$ or IL-12/IL-23 are now widely

Address for correspondence: Bartłomiej Kwiek MD, Department of Dermatology and Immunodermatology, Medical University of Warsaw, 82A Koszykowa St, 02-008 Warsaw, Poland, phone: +48 608307 575, e-mail: bartlomiej@kwiek-dermatolog.pl Received: 27.01.2016, accepted: 18.04.2016. 
used in the treatment of moderate to severe psoriasis, for both induction and long-term disease-control therapy. It has been speculated that some psoriasis therapies may increase CVD, while others may decrease CVD, and there is mounting evidence of a reduction in the CVD risk following anti-TNF- $\alpha$ treatment [20]. It is still unclear whether the reduction in CVD after such treatment is drug-specific or follows adequate control of skin and/ or joint disease. Biomarkers of such control should be available.

Platelet activation markers are good candidates for such biomarkers [13]. There are several direct and indirect methods of platelet activation measurements. Soluble P-selectin is well-established and reliable, and is one of the most accessible indirect markers of platelet activation [13].

\section{Aim}

The aim of this study is thus to confirm previous observations of increased platelet activity in chronic plaque psoriasis in a selected subgroup of patients qualified to biological treatment. We also wanted to confirm whether the severity of the disease, as measured by the psoriasis area and severity index (PASI), is correlated with platelet activity in these patients. Further, we wanted to monitor platelet activity during long-term therapy with etanercept, infliximab, adalimumab, and ustekinumab.

\section{Material and methods}

The study was designed as an observational cohort study; the procedures followed were in accordance with the Helsinki Declaration of 1975, as revised in 1983, and approved by the local ethical committee. Patients with chronic plaque psoriasis who had been qualified to biological treatment at the Department of Dermatology, Medical University of Lodz were enrolled to this study after giving their informed consent. The decision to employ biological treatment was based on the following criteria: PASI > 10 or body surface area (BSA) $>10 \%$ or dermatological life quality index (DLQI) greater than 10 and lack of any contraindications for biological treatment such as tuberculosis, or history of cancer. In addition, patients needed to be resistant to or otherwise unable to use phototherapy, methotrexate, or cyclosporine $A$.

Patients who had undergone systemic therapy (whether classic or biological) during the 4 weeks prior to the beginning of the treatment were excluded. So were patients with diseases or clinical situations that could influence platelet activation, such as other inflammatory skin diseases, arthritis other than psoriatic arthritis (PsA), chronic or acute inflammatory diseases, current severe infections, surgery within the last month, venous or arterial thromboembolism within the last 3 months, anticoagulation with vitamin $\mathrm{K}$ antagonists or low molecular weight heparin in the last 14 days, and uncontrolled diabetes. After excluding 2 patients because of their previous treatment with systemic therapy within the 4 weeks prior to the onset of the study, a total of 27 Caucasian patients (25-65 years old, mean: 50 ) treated with infliximab (6), adalimumab (12), etanercept (5), or ustekinumab (4) were included into the study. All drugs were dosed in accordance with standard regimens for chronic plaque psoriasis: infliximab $5 \mathrm{mg} / \mathrm{kg}$ intravenously followed by additional doses at week 2 and 6 and every 8 weeks thereafter, adalimumab 80 mg subcutaneously (s.c.) at week 0 and $40 \mathrm{mg}$ on every other week starting 1 week after the initial dose, etanercept $50 \mathrm{mg}$ s.c. per week in 2 patients and $2 \times 50 \mathrm{mg}$ s.c. weekly in 3 patients, $45 \mathrm{mg}$ of ustekinumab s.c. at week 0,4 and every 12 weeks later on (all patients weighed $\leq 100 \mathrm{~kg}$ ). Disease severity assessment (PASI), platelet activity (serum P-selectin), and serum IL-6 were evaluated before and monitored during the treatment, for up to 12 months (3 to 12 months; mean: 9.4 months). Thirty three ageand sex-matched healthy control individuals from the same region of Poland were checked for serum P-selectin and IL-6.

Blood for cytokine analysis was collected from antecubital vein and centrifuged for $10 \mathrm{~min}$ at $1600 \mathrm{~g}$ to obtain serum that was immediately frozen. Aliquots were stored in $-80^{\circ} \mathrm{C}$ until further use. P-selectin and IL- 6 were measured with ELISA kits (R\&D systems) and duplicate measurements were carried out according to the manufacturer's instructions.

\section{Statistical analysis}

Statistical analysis was performed with Statistica 10.0 software (StatSoft). Data characterized by a normal distribution are expressed as means \pm standard errors of the mean (SEM). Parameters not displaying such a distribution are expressed as medians with ranges, maximum and minimum. Student's and Wilcoxon tests were used for comparison between two related groups and Mann-Whitney test for unrelated ones. Friedman test was used for comparison across multiple test attempts. Correlations are estimated according to Spearman's rank correlation method. All $p$-values $<0.05$ were considered statistically significant.

\section{Results}

We found no significant difference in serum P-selectin levels between our cohort of patients and the healthy controls $(133.76 \mathrm{ng} / \mathrm{ml}$, ranging from $74.13 \mathrm{ng} / \mathrm{ml}$ to $274.47 \mathrm{ng} / \mathrm{ml}$ vs. $153.53 \mathrm{ng} / \mathrm{ml}$, ranging from $72.08 \mathrm{ng} /$ $\mathrm{ml}$ to $195.79 \mathrm{ng} / \mathrm{m}$, respectively) (Figure 1) and no correlation between PASI and serum P-selectin level before the treatment (Figure 2). 
The PASI and IL-6 levels were reduced significantly after 3 months of therapy, while serum P-selectin did not change significantly (Figure $3 \mathrm{~A}$ ). When patients treated with different drugs were analyzed separately, P-selectin was not changed significantly either (Figure 3 B). Further treatment for up to 12 months was continued in 17 out of 23 patients and did not change P-selectin level either (Figure 4).

Sub-group analysis of patients who had an elevated serum level of P-selectin at baseline (> $200 \mathrm{pg} / \mathrm{ml}$ ) showed a significant reduction in platelet activity after 3 months of treatment. What is more, this effect sustained after 6 and 12 months of the observation (Figure 5).

\section{Discussion}

We were unable to confirm previous reports of elevated markers of platelet activity in psoriatic patients compared to healthy controls. There may be several reasons for this finding, of which one is the small sample size of 27 patients. The sample sizes employed in previous studies that have proven this hypothesis varied between 8 and 106 (Table 1) [13-19, 21, 22].

Another possibility is the influence of joint disease. An association between psoriatic arthritis and platelet activation has been previously reported [15, 21, 23, 24]. Up to $40 \%$ of psoriatic patients have joint disease, and a clear cut-off point between skin and joint input to the induction of platelet activation in these patients cannot be easily indicated. The status of joint disease was not reported in the majority of previous studies focused on skin psoriasis (Table 1). Analysis of patients with P-selectin $>200 \mathrm{ng} / \mathrm{ml}$ has shown slightly higher rates of PsA within this group (Table 2, not significant), but arthritis severity was not studied.

The other explanation for not finding a significant elevation of soluble P-selectin in our study population is that the patients included generally had PASI values of around 10 , with only 4 patients having PASI $>12$. In previous studies, patients with more severe disease were

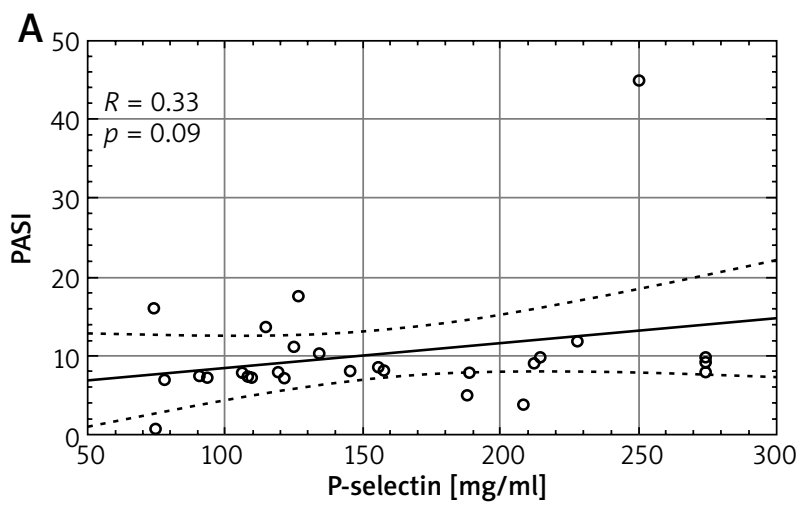

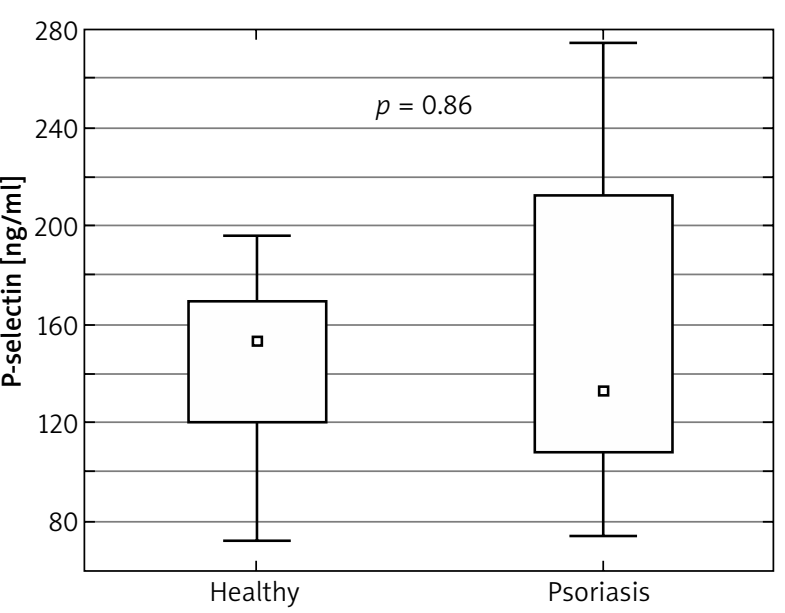

Figure 1. P-selectin levels do not differ significantly between healthy controls and patients with psoriasis before treatment

$N=33$ and 27 for controls and patients, respectively. Median, 25$75 \%$ and ranges are presented.

included, and one study has shown that in patients with mild disease, platelet activation was similar to the control group (Table 1) [18].

This is probably also important for the lack of correlation between PASI and P-selectin in our patients. One of the biggest limitations of measuring disease severity with PASI is its lack of sensitivity for mild disease. All values between one and nine percent of the affected area are given a grade of one, although the surface described may be nine times bigger. This indicates that there could be a certain threshold point where platelets are activated.

The question remains if there are differences between evaluated drugs in their influence on platelet activity. We were not able to see a statistically significant reduction in serum P-selectin when the subgroups of patients treated with different drugs were analyzed separately (Figure 3 B).

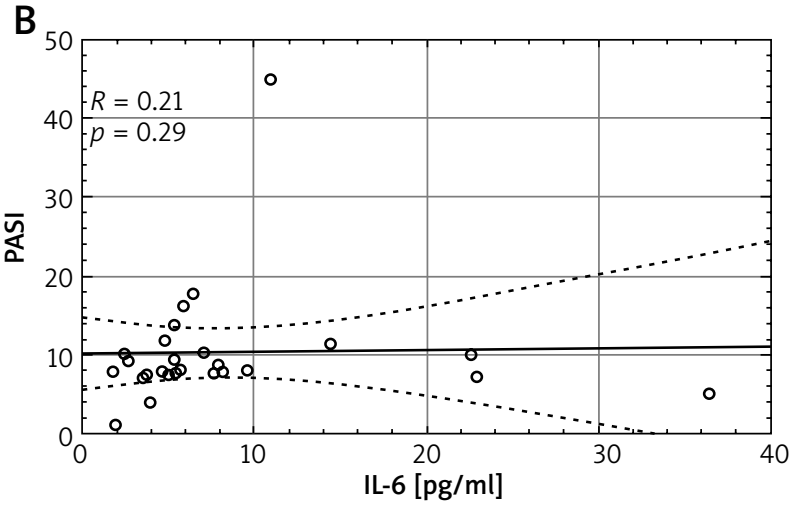

Figure 2. We found no correlation between PASI and serum P-selectin before the treatment. No such correlation was found for PASI and IL-6 either 
A

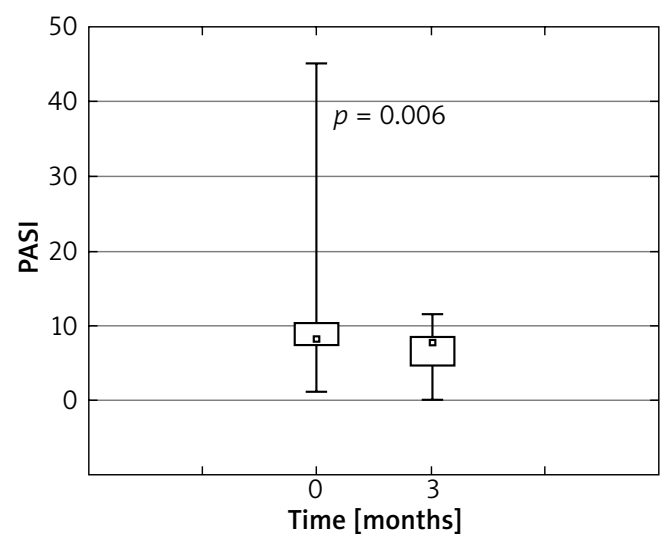

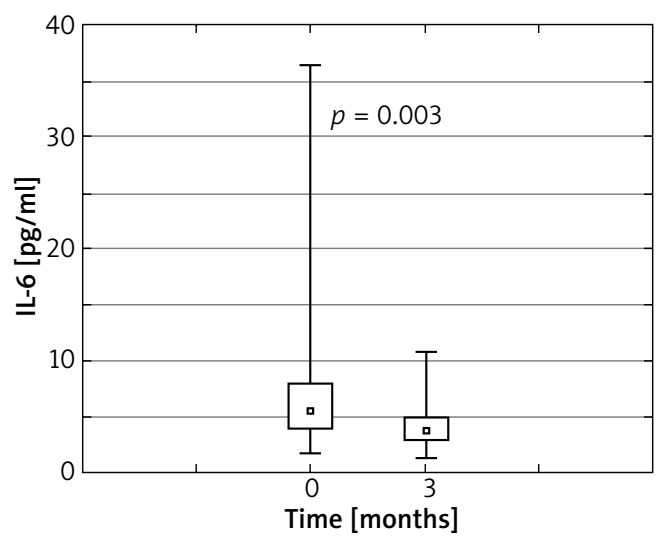

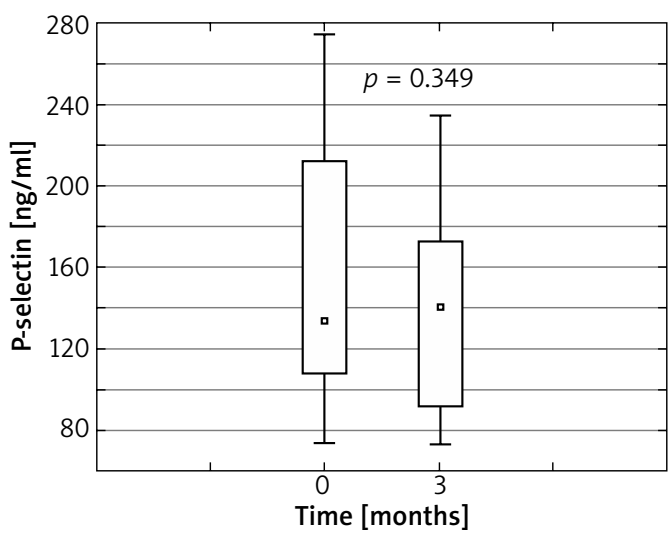

B
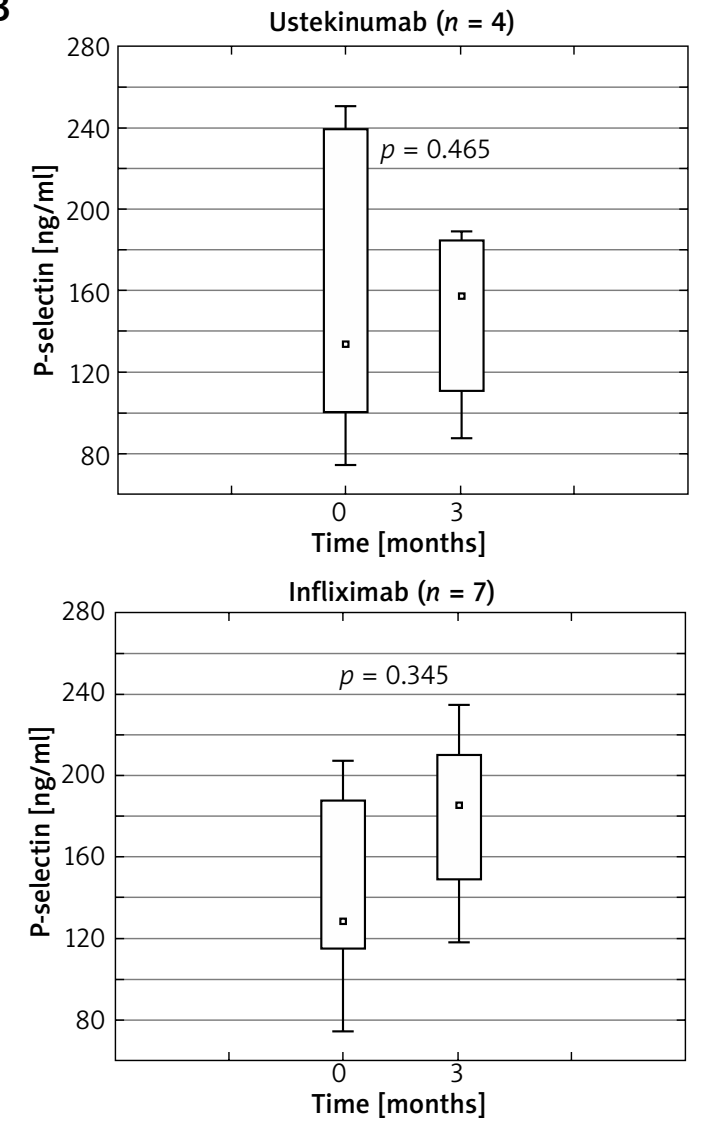

Adalimumab $(n=12)$
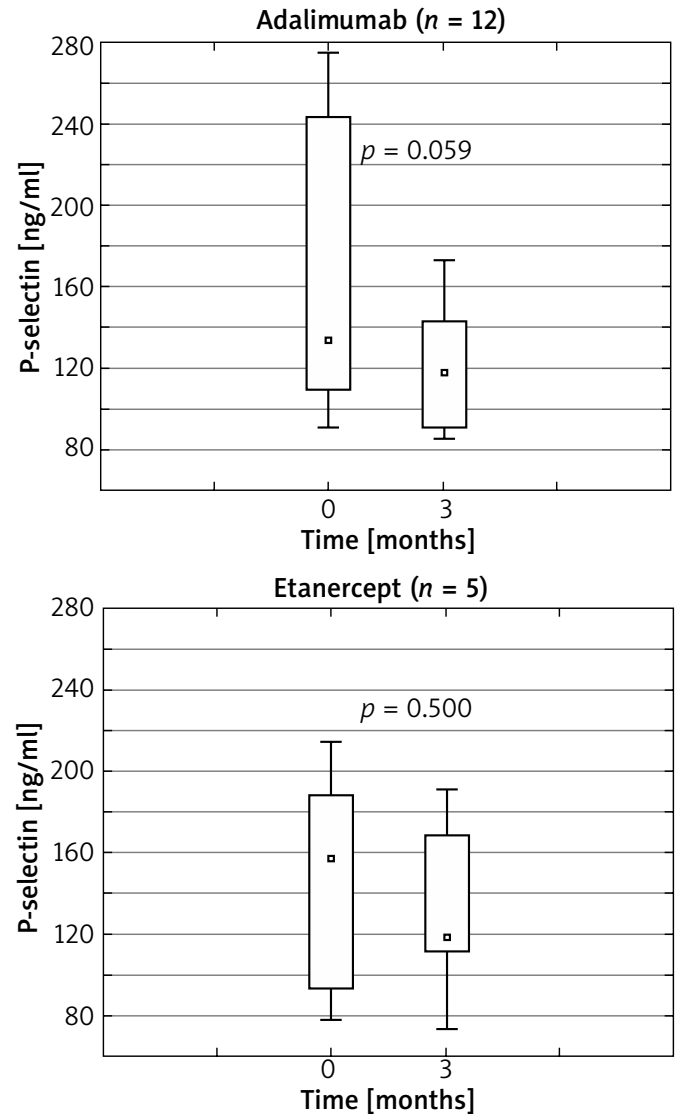

Figure 3. A - A reduction in PASI and serum IL-6 but not in serum P-selectin was seen after 3 months of treatment (all patients 27). B - Analysis of serum P-selectin change in subgroups treated with various drugs during 3 months of treatment - not significant changes were observed Medians, 25-75\% and ranges are presented. 

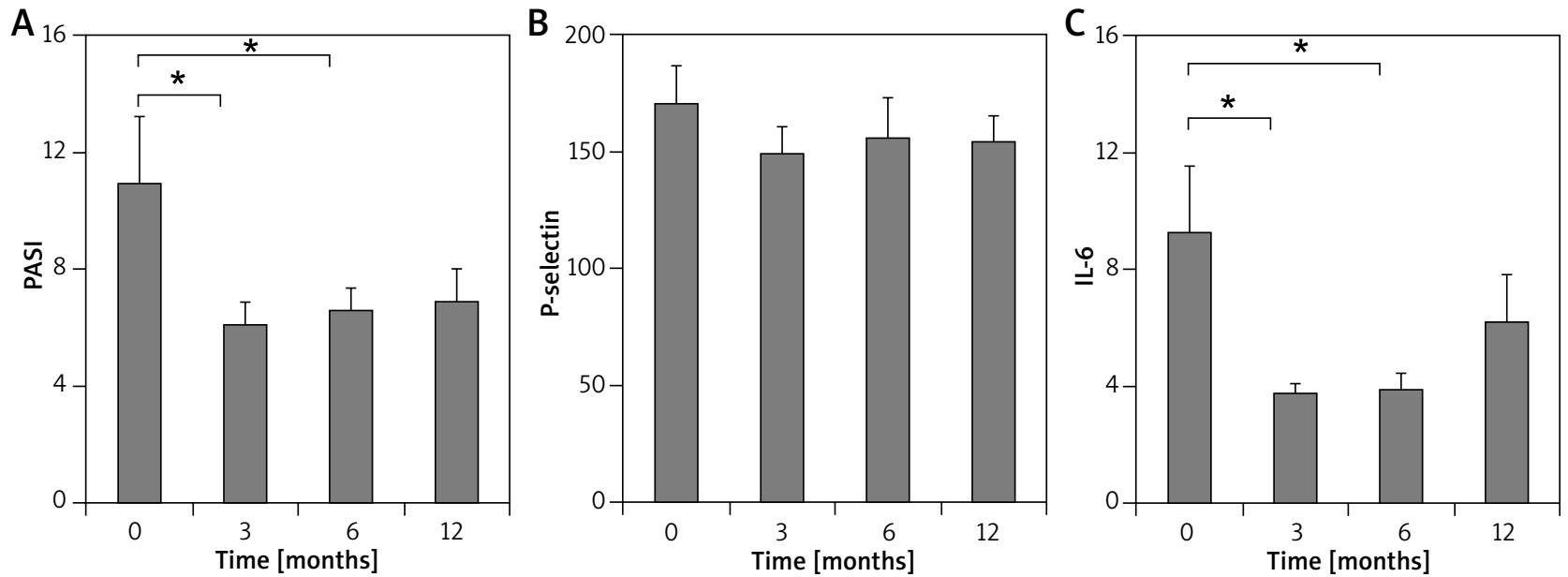

Figure 4. Treatment for up to 12 months was continued in 17 patients. Analysis of this group is presented in diagrams. The PASI (A) and IL-6 (C) were reduced throughout the treatment while P-selectin (B) was not significantly altered Means \pm standard errors of the mean are presented.
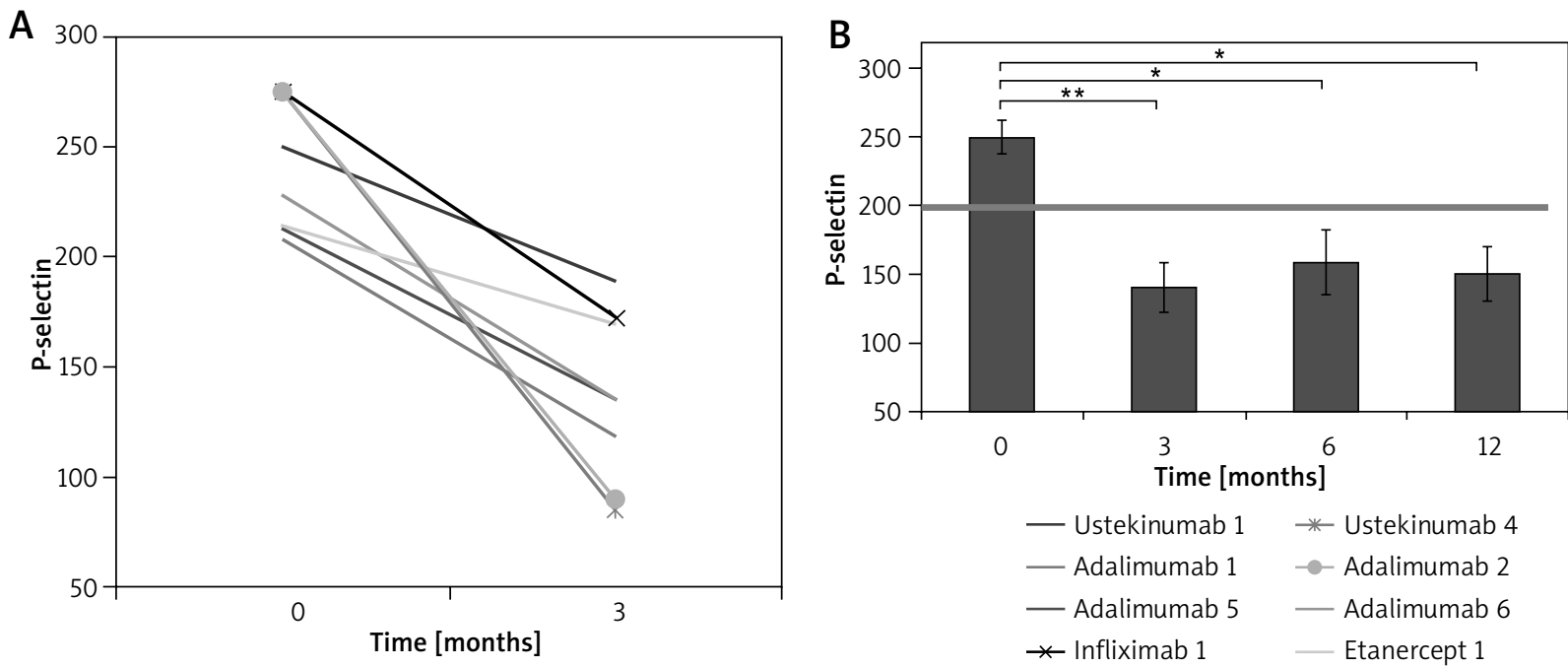

Figure 5. A - A reduction of P-selectin during 3 months of treatment in all 8 patients with elevated P-selectin before treatment (P-selectin $>200 \mathrm{ng} / \mathrm{ml}$ ) regardless of the drug used. B - In patients who have continued the treatment throughout 12 months, a reduction in P-selectin was sustained $(n=6)$

A subgroup of patients (8 out of 27 ) had serum P-selectin $>200 \mathrm{ng} / \mathrm{ml}$, a level not observed in any of healthy individuals from the control group. We have seen a reduction in P-selectin levels during 12 months of treatment only in these patients, which indicates that both anti-TNF- $\alpha$ and anti-IL-12/23 normalize rather than decrease platelet activation.

\section{Conclusions}

The results of our study suggest that in patients with relatively low PASI, there are some who already show increased platelet activation. Identifying these patients could help in choosing an adequate treatment to reduce platelet activity - a well-established risk factor for CVD. Our findings suggest that treatment modalities based on biological interventions with either anti-TNF- $\alpha$ or antiIL-12/23 are good candidates for long-term treatments that can control platelet activation.

\section{Acknowledgments}

The study was supported by Project of National Center of Science, Grant No. UMO-2013/11/B/NZ5/00037. and Medical University of Warsaw grant no.: 1M4/W1/10. 
Table 1. Studies reporting on markers of platelet activation in psoriasis

\begin{tabular}{|c|c|c|c|c|c|c|}
\hline Study & $N$ & PASI & $N$ of PsA & $\begin{array}{l}\text { Treatment } \\
\text { duration }\end{array}$ & $\begin{array}{l}\text { Platelet activation } \\
\text { marker }\end{array}$ & $\begin{array}{l}\text { Platelet activity and PASI } \\
\text { correlation }\end{array}$ \\
\hline $\begin{array}{l}\text { Ludwig et al., } \\
2004\end{array}$ & 8 & $\begin{array}{l}4 / 8 \text { patients with PASI } \\
\text { of around } 20 \text { or more }\end{array}$ & NR & Mean 27 days & P-selectin & $\begin{array}{l}\text { Positive, based on pre- and } \\
\text { post-treatment }\end{array}$ \\
\hline $\begin{array}{l}\text { Karabudak et al., } \\
2008\end{array}$ & 20 & $13 \pm 7$ & NR & NR & MPV & $\begin{array}{c}\text { Higher level when compared } \\
\text { with healthy controls but no } \\
\text { correlation }\end{array}$ \\
\hline $\begin{array}{l}\text { Tamagawa- } \\
\text { Mineoka et al., } \\
2010\end{array}$ & 21 & $\begin{array}{l}\text { Median PASI: } 16.2 ; \\
\text { range: } 12.2-18.7\end{array}$ & NR & $\begin{array}{l}4 \text { patients for } \\
4 \text { weeks }\end{array}$ & $\begin{array}{l}\text { sP-selectin } \\
\text { PDMP }\end{array}$ & $\begin{array}{l}\text { Positive, based on } \\
\text { pretreatment }\end{array}$ \\
\hline $\begin{array}{l}\text { Canpolat et al., } \\
2010\end{array}$ & 106 & $\begin{array}{c}\text { PASI } 17 \text { in patients with } \\
\text { PsA and } 10.7 \text { in patients } \\
\text { without PsA }\end{array}$ & 48 & Not treated & MPV & Positive \\
\hline $\begin{array}{l}\text { Garbaraviciene } \\
\text { et al., } 2010\end{array}$ & 47 & $\begin{array}{l}\text { Not stated (moderate to } \\
\text { severe disease) }\end{array}$ & NR & $\begin{array}{c}\text { Time of } \\
\text { hospitalization } \\
\text { (not specified) }\end{array}$ & $\begin{array}{l}\text { P-selectin and } \\
\text { sP-selectin }\end{array}$ & $\begin{array}{l}\text { Positive, based on pre- and } \\
\text { post-treatment }\end{array}$ \\
\hline $\begin{array}{l}\text { Pelletier et al., } \\
2011\end{array}$ & 52 & $18(14-25)$ & NR & Not treated & PDMP & $\begin{array}{l}\text { Higher level when compared } \\
\text { with healthy controls but no } \\
\text { correlation }\end{array}$ \\
\hline $\begin{array}{l}\text { Saleh et al., } \\
2013\end{array}$ & 25 & $\begin{array}{l}\text { Mean PASI } 30 \text { for male } \\
\text { and } 15 \text { for female }\end{array}$ & NR & Not treated & $\begin{array}{l}\text { P-selectin } \\
\text { MPV }\end{array}$ & $\begin{array}{l}\text { Positive for moderate to severe } \\
\text { disease when measured with } \\
\text { P-selectin, not present for mild } \\
\text { psoriasis }\end{array}$ \\
\hline $\begin{array}{l}\text { Capo et al., } \\
2014\end{array}$ & 59 & 15.5 & 27 & $\begin{array}{l}\text { Anti-TNF- } \alpha \text { for } 6 \\
\text { months }\end{array}$ & MPV & Reverse correlation with MPV \\
\hline $\begin{array}{l}\text { Takeshita et al., } \\
2014\end{array}$ & 53 & $\begin{array}{l}3 \text { patients with } \\
\text { BSA > 10; } 21 \text { patients } \\
\text { with BSA 3-10 }\end{array}$ & 15 & $\begin{array}{l}\text { Patients on } \\
\text { treatment }\end{array}$ & PDMP & $\begin{array}{l}\text { Higher level when compared } \\
\text { with healthy controls but no } \\
\text { correlation }\end{array}$ \\
\hline
\end{tabular}

$N$ - number of patients, PSA - psoriatic arthritis, NR - not reported, MPV - mean platelet volume, sP-selectin-soluble P-selectin, PDMP-platelet-derived microparticles.

Table 2. Basic characteristics of two subgroups of patients: those with high ( $>200 \mathrm{ng} / \mathrm{ml})$ and those with low $(<200 \mathrm{ng} / \mathrm{ml})$ serum P-selectin levels

\begin{tabular}{lcc}
\hline Parameter & $\begin{array}{c}\text { P-selectin } \\
\text { high }\end{array}$ & $\begin{array}{c}\text { P-selectin } \\
\text { low }\end{array}$ \\
\hline Number of patients & 8 & 19 \\
\hline PASI & 13.1 & 8.8 \\
\hline PsA, $n(\%)$ & $4(50)$ & $5(26)(\mathrm{NS})$ \\
\hline Gender (M/F) & $4 / 4$ & $11 / 8(\mathrm{NS})$ \\
\hline Age [years] & 46.4 & $52.2(\mathrm{NS})$ \\
\hline
\end{tabular}

NS - not significant difference.

\section{Conflict of interest}

The authors declare no conflict of interest.

\section{References}

1. Nestle FO, Kaplan DH, Barker J. Psoriasis. N Engl J Med 2009; 361: 496-509.

2. Li WQ, Han JL, Manson JE, et al. Psoriasis and risk of nonfatal cardiovascular disease in U.S. women: a cohort study. $\mathrm{Br}$ J Dermatol 2012; 166: 811-8.
3. Mehta NN, Yu Y, Pinnelas R, et al. Attributable risk estimate of severe psoriasis on major cardiovascular events. Am J Med 2011; 124: 775e1-6.

4. Xu T, Zhang YH. Association of psoriasis with stroke and myocardial infarction: meta-analysis of cohort studies. $\mathrm{Br}$ J Dermatol 2012; 167: 1345-50.

5. Ahlehoff O, Gislason GH, Lindhardsen J, et al. Prognosis following first-time myocardial infarction in patients with psoriasis: a Danish nationwide cohort study. J Intern Med 2011; 270: 237-44.

6. Van de Kerkhof PC. Psoriasis more than skin deep. J Dermatolog Treat 2008; 19: 4.

7. Gottlieb AB, Chao C, Dann F. Psoriasis comorbidities. J Dermatolog Treat 2008; 19: 5-21.

8. Henseler T, Christophers E. Disease concomitance in psoriasis. J Am Acad Dermatol 1995; 32: 982-6.

9. Bańska-Kisiel K, Haberka M, Bergler-Czop B, et al. Carotid intima-media thickness in patients with mild or moderate psoriasis. Adv Dermatol Allergol 2016; 33: 286-9.

10. Kostrubiec M, Labyk A, Pedowska-Wloszek J, et al. Mean platelet volume predicts early death in acute pulmonary embolism. Heart 2010; 96: 460-5.

11. Jennings LK. Role of platelets in atherothrombosis. Am J Cardiol 2009; 103 (3 Suppl): 4A-10A.

12. Patrono C, Andreotti F, Arnesen H, et al. Antiplatelet agents for the treatment and prevention of atherothrombosis. Eur Heart J 2011; 32: 2922-32. 
13. Garbaraviciene J, Diehl S, Varwig D, et al. Platelet P-selectin reflects a state of cutaneous inflammation: possible application to monitor treatment efficacy in psoriasis. Exp Dermatol 2010; 19: 736-41.

14. Ludwig RJ, Schultz JE, Boehncke WH, et al. Activated, not resting, platelets increase leukocyte rolling in murine skin utilizing a distinct set of adhesion molecules. J Invest Dermatol 2004; 122: 830-6.

15. Canpolat F, Akpinar H, Eskioglu F. Mean platelet volume in psoriasis and psoriatic arthritis. Clin Rheumatol 2010; 29: 325-8.

16. Tamagawa-Mineoka R, Katoh N, Kishimoto S. Platelet activation in patients with psoriasis: increased plasma levels of platelet-derived microparticles and soluble P-selectin. J Am Acad Dermatol 2010; 62: 621-6.

17. Pelletier F, Garnache-Ottou F, Angelot F, et al. Increased levels of circulating endothelial-derived microparticles and small-size platelet-derived microparticles in psoriasis. J Invest Dermatol 2011; 131: 1573-6.

18. Saleh HM, Attia EA, Onsy AM, et al. Platelet activation: a link between psoriasis per se and subclinical atherosclerosis: a case-control study. Br J Dermatol 2013; 169: 68-75.

19. Takeshita J, Mohler ER, Krishnamoorthy P, et al. Endothelial cell-, platelet-, and monocyte/macrophage-derived microparticles are elevated in psoriasis beyond cardiometabolic risk factors. J Am Heart Assoc 2014; 3: e000507.

20. Hugh J, Van Voorhees AS, Nijhawan RI, et al.; Medical Board of the National Psoriasis Foundation. The risk of cardiovascular disease in individuals with psoriasis and the potential impact of current therapies. J Am Acad Dermatol 2014; 70: 168-77.

21. Capo A, Di Nicola M, Auriemma M, et al. Mean platelet volume variation after biologic therapy in psoriasis and psoriatic arthritis. Eur J Dermatol 2014; 24: 133-5.

22. Karabudak O, Ulusoy RE, Erikci AA, et al. Inflammation and hypercoagulable state in adult psoriatic men. Acta Derm Venereol 2008; 88: 337-40.

23. Di Minno MN, lervolino S, Peluso R, et al. Platelet reactivity and disease activity in subjects with psoriatic arthritis. J Rheumatol 2012; 39: 334-6.

24. MacMullan P. Guilty by association: platelet reactivity and inflammation in psoriatic arthritis. J Rheumatol 2012; 39: 210-1. 